\title{
Food Wastage Attitudes among the United Arab Emirates Population: The Role of Social Media
}

\author{
Tareq M. Osaili 1,2,3,*, Reyad S. Obaid ${ }^{1,3}$, Russul Alqutub ${ }^{1}$, Rawya Akkila ${ }^{1}$, Ala Habil ${ }^{1}$, Ahlam Dawoud ${ }^{1}$, \\ Serin Duhair $^{1}$, Fayeza Hasan ${ }^{3}$, Mona Hashim ${ }^{1,3}$, Leila Cheikh Ismail 1,3 ${ }^{\mathbb{D}}$, Anas A. Al-Nabulsi ${ }^{2}$ and Sadi Taha ${ }^{4}$
}

\section{check for}

Citation: Osaili, T.M.; Obaid, R.S.; Alqutub, R.; Akkila, R.; Habil, A.; Dawoud, A.; Duhair, S.; Hasan, F.; Hashim, M.; Ismail, L.C.; et al. Food Wastage Attitudes among the United Arab Emirates Population: The Role of Social Media. Sustainability 2022, 14, 1870. https://doi.org/10.3390/ su14031870

Academic Editor: Azzurra Annunziata

Received: 14 December 2021

Accepted: 27 January 2022

Published: 7 February 2022

Publisher's Note: MDPI stays neutral with regard to jurisdictional claims in published maps and institutional affiliations.

Copyright: (C) 2022 by the authors. Licensee MDPI, Basel, Switzerland. This article is an open access article distributed under the terms and conditions of the Creative Commons Attribution (CC BY) license (https:// creativecommons.org/licenses/by/ $4.0 /)$.
1 Department of Clinical Nutrition and Dietetics, College of Health Sciences, University of Sharjah, Sharjah P.O. Box 27272, United Arab Emirates; robaid@sharjah.ac.ae (R.S.O.); u14121658@sharjah.ac.ae (R.A.); u14120257@sharjah.ac.ae (R.A.); u14120259@sharjah.ac.ae (A.H.); u14120130@sharjah.ac.ae (A.D.); u14123520@sharjah.ac.ae (S.D.); mhashim@sharjah.ac.ae (M.H.); lcheikhismail@sharjah.ac.ae (L.C.I.)

2 Department of Nutrition and Food Technology, Faculty of Agriculture, Jordan University of Science and Technology, P.O. Box 3030, Irbid 22110, Jordan; anas_nabulsi@just.edu.jo

3 Sharjah Institute for Medical Research, University of Sharjah, Sharjah P.O. Box 27272, United Arab Emirates; U00040620@sharjah.ac.ae

4 School of Business Administration, Al Dar University College, Dubai P.O. Box 35529, United Arab Emirates; sadi@aldar.ac.ae

* Correspondence: tosaili@sharjah.ac.ae or tosaili@just.edu.jo

\begin{abstract}
The objective of this study is to evaluate food wastage attitudes and the impact of social media among the United Arab Emirates (UAE) population. A questionnaire was distributed via social network applications $(n=525)$. The majority of the respondents were females $(84 \%)$ and social media users $(99 \%)$. Most of the respondents were well aware of the problem of food wastage $(96 \%)$. Half of the respondents (53.7 and 48.8\%) reported taking some form of action on an 'often' basis to reduce food wastage, and buying food as per their needs, respectively. Two-thirds (66.7\%) of the respondents stated that their family did not throw away anything from their last meal. A majority (82.3\%) felt uncomfortable upon discarding food. A mixed response was observed in terms of food wastage and social media usage. On one hand, using social media was significantly $(p<0.05)$ associated with measuring the exact quantity of ingredients prior to preparation, lower overall family wastage, eating leftovers, and composting. On the other hand, less-frequent social media users significantly $(p<0.05)$ had fewer leftovers, checked expiry dates, were more serious about food wastage, and planned to minimize it. Social media should be used with prudence as it may not have a very significant impact on food wastage reduction.
\end{abstract}

Keywords: food waste; social media; knowledge assessment; households; behavioral changes; composting

\section{Introduction}

The term 'food waste' refers to all foods and foodstuffs produced for human consumption that are disposed or lost [1]. The deliberate discarding of food may occur at all stages of the supply chain [2]. The economic costs associated with food wastage are substantial and amount to about USD 1 trillion per year [3]. In Abu Dhabi (the capital of the United Arab Emirates (UAE)), about 12.84 million tonnes of food waste was generated [4]. There is both an economical and an ethical aspect to food wastage [1]. The net food wasted around the world has the potential to feed about 2 billion people, which is double the number of the undernourished population worldwide [5].

Food waste is not restricted to edible items alone; non-edible items (e.g., seeds, skin, etc.), losses due to natural causes such as infestations or industrial residues are also counted towards food wastage [6]. In the developed world, losses are mostly towards the later stages of the food chain (during the retail, food service, and home stages). The trend of consumers purchasing beyond their needs and then simply throwing away the edible 
foodstuffs due to spoilage or lack of use are some common reasons [2]. These countries waste food equivalently to the annual food production of the entirety of sub-Saharan Africa [5]. In contrast, the developing world loses its produce mainly at the earlier stages of the food supply chain: extreme climatic conditions, lack of transport, poor harvesting technologies, and storage capacities are some predominant factors $[1,7,8]$. Although various attempts have been made to extract bioactive compounds/nutraceuticals from food waste, the processes are not worked upon on a larger scale [9].

Worldwide, more than half of the food produced is wasted, lost, or discarded [10]. The need to address food wastage is increasingly gaining importance due to a growing world population, adverse effects on the environment, and rising food security concerns [11]. The environmental impact of food wastage is quite baffling. Global food wastage decomposition is considered the third-largest contributor to the production of methane (a greenhouse gas). Oil, water, and land - essential entities required for food production-are also wasted upon discarding food. It was reported that the amount of water used for irrigation of crops that would eventually be wasted is equivalent to three times the volume of Lake Geneva [12]. The environmental impact of food wastage varies with the type of food item [13] and its associated attributes (organic/conventional, water footprint, etc.) [14].

Understanding the factors that lead to food wastage might help in combating it better. Previous studies indicated that knowledge pertaining to food waste varies with a vast margin; some studies reported that about $90 \%$ of their respondents understood the problem food waste poses [15-18], while in some studies this figure was less than $50 \%[19,20]$. Understanding the seriousness of this problem is expected to play a role in reducing overall discarding rates.

The UAE is a country in the Arabian Peninsula with an average population of 10 million [21]. Only $0.5 \%$ of the land is arable, with less than $5 \%$ being used for agriculture purposes [21]. Most of the country's population consists of expatriates, with only $11.6 \%$ of the population being local [21]. The country has actively championed the cause of reducing food wastage by supporting various platforms such as the Winnow App [22] and the UAE Food Bank Initiative [23]. Interestingly, previous studies have used social media as a tool to combat food wastage $[24,25]$. This is a very interesting strategy, as it is economical (in terms of cost and time) and easily accessible to the public. More than $80 \%$ of the UAE population lives in urban areas and $98.5 \%$ of its population has access to the Internet [21]. The country has a literacy rate of $97.5 \%$ [26].

It is probable that social media users come across some text/graphic content pertaining to world hunger, famine, food wastage, or the environmental impacts of cash crops, and hence might be more prone to thinking twice before discarding/wasting any food. Therefore, the objective of this study is to evaluate food wastage attitudes and the impact of social media amongst the UAE population.

\section{Materials and Methods}

\subsection{Questionnaire Design}

A question bank was prepared using items based on informant interviews of households and previously validated published articles $[15,18,27,28]$. Overall, there were 35 questions on food wastage attitudes of households and the usage of social media in the question bank. The content in the question bank was reviewed by three experts on food safety and behaviors to check for relevance of the items to the research objectives (on a scale from 1 to 10). The experts also evaluated the rationality of the answer settings, clarity and understanding of items, and whether the items overlapped. The overall average for each response was calculated to evaluate question validity. Items that scored 7 or more were included in the questionnaire. Some of the questions were excluded because as per experts' opinions, they did not meet study objectives and were deemed to be repetitive by the reviewers. The experts agreed that the questionnaire contained items which covered all aspects of the construct being measured. They also agreed that the questions were clear. 
Therefore, out of 35 questions, 26 were selected: 21 questions related to awareness and behaviors concerning food wastage, and 5 related to the usage of social media. After the finalization of the English version of the questionnaire, two Arabic and English bilingual experts forward-translated the questionnaire from English to Arabic. Another set of bilingual experts performed a back-translation from Arabic to English. The researchers then compared the original and the back-translated versions, and solved discrepancies with discussion.

A pilot study was also performed on 30 participants to confirm the clarity of questions and to evaluate response time. The respondents took 15-20 min to complete the questionnaire and gave no comments for further improvement. The reliability of the questionnaire (consistency) was evaluated using the alpha Cronbach factor [29,30]. The final version of the questionnaire consisted of 21 questions related to awareness and behaviors concerning food wastage, 5 questions related to usage of social media, and 7 questions dealing with socio-demographic variables (age, gender, nationality, number of family members, monthly household income, educational level, and family member responsible of food preparation). A consent form had to be signed by the respondent prior to attempting the questionnaire. The department of Clinical Nutrition and Dietetics (University of Sharjah) approved the project (Reference \# 3/2018). The questionnaire was disseminated via Google forms.

\subsection{Data Collection}

Data collection was performed in a convenient, cross-sectional manner using social network applications (Instagram ${ }^{\circledR}$, Whatsapp $^{\circledR}$, and Twitter ${ }^{\circledR}$ ). A page titled (@ connectosave) was developed on Instagram for publicity purposes for the same. A total of 525 household representatives from the UAE responded to the questionnaire. The sample size was calculated based on a formula that is used in cross-sectional studies that aims to measure prevalence. The minimum required sample size was calculated based on a response distribution of $50 \%$, confidence level of $95 \%$, and margin of error of $5 \%$. The population size of the country is 9.89 million; thus, a minimum sample size of 385 was required [31]. The sample size in the study exceeded the minimum required number. The study spanned a period from February to April in the year 2018.

\subsection{Data Analysis}

The data was analyzed using IBM SPSS ${ }^{\circledR}$ (Version 22). Descriptive statistical analysis (frequencies, percentages) was performed to summarize the sociodemographic characteristics and distribution of respondents. The descriptive Chi square test was used to determine an association between the existence of food waste and the respondents' characteristics or behavioral habits.

\section{Results and Discussion}

The alpha Cronbach factor calculation of the questionnaire indicated that the constructs in the questionnaire were reliable (0.84). The results of the questionnaire are summarized in the following sections. The majority (84\%) of the respondents in this study were females (Table 1). The age bracket which was most predominant was 20-30 years $(54.5 \%)$. This is understandable, as social media is usually very common amongst this age group. More than half (65\%) of the respondents had between 5 and 8 members constituting the household. Almost all (99\%) of the respondents reported using social media (Instagram/Facebook/WhatsApp). A majority checked social media sites on an hourly basis (61.0\%). A good percentage (40.6\%) reported spending 3-5 h on social media per day. The average family income was $<20,000$ and 20,000-40,000 AED (1 AED = 0.27 USD) for 36.2 and $37.7 \%$ of the respondents, respectively. The mother was the predominant person responsible for cooking in the household (61.1\%). 
Table 1. Sociodemographic characteristics and distribution of respondents $(n=525)$.

\begin{tabular}{cccc}
\hline Parameter & & $\mathbf{N}$ & $\%$ \\
\hline \multirow{3}{*}{ Age } & $<20$ & 127 & $24.2 \%$ \\
& $20-30$ & 286 & $54.5 \%$ \\
& $30-40$ & 61 & $11.6 \%$ \\
Gender & $40-60$ & 50 & $9.5 \%$ \\
& $>60$ & 1 & $0.2 \%$ \\
Nationality & Female & 442 & $84.2 \%$ \\
& Male & 83 & $15.8 \%$ \\
Family Members & Local & 95 & $18.1 \%$ \\
& Non-Local & 430 & $81.9 \%$ \\
Monthly income & $2-4$ & 113 & $21.5 \%$ \\
(DHS) & $5-8$ & 340 & $64.8 \%$ \\
& $>8$ & 72 & $13.7 \%$ \\
& $<20,000$ & 190 & $36.2 \%$ \\
& $20,000-40,000$ & 198 & $37.7 \%$ \\
Food Preparation & $>40,000$ & 107 & $20.4 \%$ \\
& Myself & 111 & $21.1 \%$ \\
& Mother & 321 & $61.1 \%$ \\
& Brother/s & 1 & $0.2 \%$ \\
& Sister/s & 1 & $0.2 \%$ \\
& Maid & 81 & $15.4 \%$ \\
& Other & 10 & $1.9 \%$ \\
\hline
\end{tabular}

The attitude towards food wastage of the respondents in this study was fair (Figure 1). About $96 \%$ of the respondents agreed that food waste is a problem. Other studies showed the agreement percentage to be 89\% (Tunisia) [15], 90\% (Czech Republic) [16], 89\% (Italy) [17], 90.8\% (Montenegro) [18], 92.7\% (North Macedonia) [27], and 95\% (Turkey) [28], respectively. However, some studies reported a lower awareness level; a study conducted by Preka et al. [19] in Albania reported only half the studied population understood the complexity of food waste, while a study conducted by Flanagan and Priyadarshini [20] in Ireland reported that a good $62.6 \%$ of respondents were 'not concerned' about food wastage. Being aware about the issue of food wastage is the primary step towards food conservation. However, high awareness levels may not necessarily translate to lower losses. There lies a possibility that people underestimate the amount of food they waste because they do not want to project themselves in a negative manner. Wasting small amounts of food but on a regular basis would also result in substantial cumulative food losses [32].

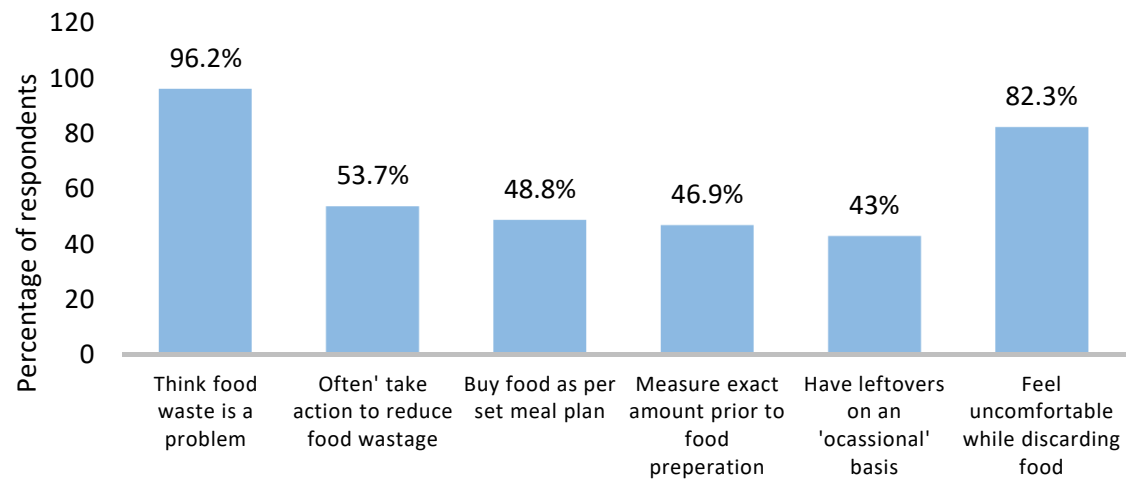

Figure 1. Attitudes of respondents pertaining to food wastage $(n=525)$.

Although a good percentage of respondents in this study were aware of the problem of food wastage, it did not translate into action. Only about half (53.7\%) of the respondents reported taking some form of action on an 'often' basis to reduce food wastage. Studies conducted in Albania [19] and Norway [33] reported that fewer than half (22.7 and 38.1\%) of their respondents took such a measure, while a study conducted in Tunisia [15] reported that $93 \%$ of the respondents took action to reduce food waste. 
In this study, about $48.8 \%$ of the respondents reported buying food as per their needs. A shopping list would be the primary option to list ingredients required for preparing regular meals [34]; around the world about $20-44 \%$ of the respondents reported always using a shopping list $[15,18,19,27,28]$. Thus, the respondents in the present study seemed to be somewhat on par with their counterparts worldwide in terms of shopping only for required items.

About $10 \%$ of the respondents purchased food commodities on a 'daily' basis, while $71 \%$ purchased them on a weekly basis. Studies conducted in Albania, Montenegro, and North Macedonia reported higher percentages with, $16.8 \%, 36.9 \%$, and $39.6 \%$ of their respondents purchasing food on a 'daily' basis $[18,19,27]$. The probability of eating fresh food is higher if the commodities are purchased on a 'daily' basis; however, this may lead to increased food wastage, especially if the leftovers mount up throughout the week. Shopping for a week would aid in better meal planning and help reduce wastage; therefore, having a lower percentage of participants purchasing food on a 'daily' basis (as observed in this study) is encouraging when dealing with food wastage [35].

'Occasional' leftovers were reported by $43.0 \%$ of the respondents. Only $14.5 \%$ of the respondents discarded their leftovers, while $72.6 \%$ reported eating them the next day. About $43.0 \%$ reported giving them away. Previous studies indicated no consistent trend regarding eating leftovers the next day, with the percentage varying from $12.7 \%$ [27] to $73.0 \%$ [18]. The practice of discarding leftovers in different parts of the world ranged from $50-75 \%[18,27,28,36]$. Keeping the above statistics in view, the respondents of this study showed a better attitude towards food wastage with a good margin. The usage of leftovers depends on various factors such as the availability of time (busy schedules are expected to increase leftover consumption), the inherent/personal concept of spoilage, the taste of the food, as well as the palatability of the leftovers $[37,38]$. It could also have a psychological angle, where more leftovers are associated with self-perceived feelings of goodness due to lower consumption [39].

Various studies with the agreement level of respondents varying from $50 \%$ to $80 \%$ have reported elongated storage periods to be a major contributing factor to food wastage $[15,18,19,27,36,40]$. In this study, more than half $(56.6 \%)$ of the respondents kept track of stored food items pertaining to how long the food was kept in the fridge or freezer, and thus playing their role in combating food waste.

Foods reaching their expiry dates have also been listed as a major factor contributing to food waste in multiple studies $[27,33,36,41]$. In this study, a good $85.1 \%$ paid attention to the expiry date while grocery shopping. In comparison, a greater number of respondents $(91.0 \%)$ in a study conducted in the USA did so [42]. Foods with late expiry dates are likely to be wasted less. The consumer should be educated to differentiate between 'best by' and 'use by' dates to further decrease the margin of food wastage.

Two-thirds $(66.7 \%)$ of the respondents in this study stated that their family did not throw away anything from their last meal. However, household helpers are usually in charge of food preparation and disposal in the region. It is probable that they may discard it, and that household members are unaware of the disposal. Different studies report $4 \%$ [28], 13\% [42], 15\% [36], 23.7\% [27], 30\% [15], and 56\% [17] of their respondents claiming that they 'never' discard food. A majority of the respondents (82.3\%) in the present study felt uncomfortable upon discarding food. In comparison, a study conducted in Greece observed that only $54 \%$ of the studied sample were very concerned when having to waste food. A similar percentage (52\%) was seen in the USA [42]. Clearly, the pain of discarding food seems to be higher in this studied population.

The food that was thrown away the most in this study was homemade/fast food $(43.0 \%)$, followed by bread $(27.8 \%)$, and fruits and vegetables $(21.1 \%)$. The food discarded the least was meat $(0.43 \%)$. This trend of fruits/vegetables/bakery/dairy being discarded at higher rates compared to meat products has been recorded in multiple studies $[16,18,27,28,41-43]$. In this scenario, the packaging of food products could also make a difference; packages which are easier to empty, compact (for storage purposes), 
or have the ability to be sealed in an airtight manner would decrease the need to discard leftovers [44]. In another study, respondents agreed that packing baked items (43\%), bagged salad (41\%), and bread (39\%) in smaller wraps would help reduce food wastage. Lower wastage of meat could be associated with its high price or because of the need of the product to be stored at frozen temperatures (hence increasing shelf life). Although no significant association between gender and the type of food wasted was observed in this study, a previous study conducted in Jordan [10] reported that females tend to waste more meat, while males tend to waste more rice when compared to their respective counterparts.

About $74 \%$ of the respondents in this study believed that food waste increased when purchases were made in large packages during offers and sales. Around 37\% [36], $39.4 \%$ [18], 31.8\% [27], and 35\% [28] of the respondents in other studies agreed with this. This indicates the high need to produce packages that do not compromise the organoleptic/nutritional properties of the enclosed food product and are easy to use/store.

In this study, very few respondents' purchases were affected by discount coupons $(7.6 \%)$, or a product on sale $(26.1 \%)$. However, an offer or price of the product were some factors which encouraged the respondents to buy (42.5 and 61.3\%, respectively). A good $93.3 \%$ of the respondents in this study bought a product if it was on sale/offer, even if not required by the respondent. Previous studies reported that 30.8\% [19], 39\% [15], and 51\% [28] of the respondents 'always' budged on offers. It was reported that males are significantly $(p<0.05)$ more affected by food prices than females [10]. Consumer shopping behavior where needs are not kept into perspective could increase food wastage substantially $[15,33,45]$.

Besides this concerning attitude, another area of perturbation in this study is the low awareness of composting; $41 \%$ of the respondents were not aware of this practice and only 8.8\% reported composting their leftovers. Previous studies indicated that $9.7 \%$ [19], 5\% [36], $3.3 \%$ [27], and 13\% [40] of their participants composted leftovers, respectively. With respect to this study, there could be another reason for not composting the leftovers besides the lack of knowledge, and that is the lack of space/fertile soil. Due to the prevalent barren sand of the desert in the region, the idea of composting might seem less rewarding.

Another domain is the storage of leftovers for later use; a mere 19.6\% reported freezing leftovers in this study. A study conducted in Tunisia [15] reported that $13 \%$ of the respondents considered freezing food in an effort to combat food wastage. Freezing is one of the best methods to preserve leftovers, and not doing so might result in their substantial disposal. The low number of respondents freezing foods in this study could possibly be attributed to the lack of space in the freezer. In the region, the majority of food items need to be stored at refrigeration/freezing temperatures because of the hot weather conditions. Hence, discarding food may seem to be a practical solution to many. Food preparers usually face a dilemma between wasting food or serving fresh foods. Food service establishments may fear the repercussions of serving stale foods on their brand image [46].

In terms of significant $(p<0.05)$ associations, an interesting observation in the study was that in smaller families (ranging from 2 to 8 persons), only 12.0\% reported discarding leftovers. However, in larger families (>8 people) about $25.0 \%$ reported doing so. Moreover, about $75 \%$ of the participants belonging to families consisting of 2 to 8 persons reported eating leftovers the next day; however, only about half of the participants $(47.2 \%)$ belonging to families consisting of $>8$ persons did so. It was expected that the needs of larger families would be higher and hence they would save more; however, the exact opposite seemed to be true in this study. As the concept of eating together as a family unit is fairly common in the region, it is probable that leftovers would not be enough to feed the entire family and hence are discarded. Moreover, storing large amounts of leftovers (as the case is with large families) daily is not expected to be a meagre task, further encouraging their disposal. The concept of having 'fresh meals' at the dinner table could also be a contributing factor. Another study [47] reported a similar observation: where a single person was reported to waste around $20 \mathrm{~kg}$ of food per year, while a household consisting of five or more members wasted $>90 \mathrm{~kg}$ on an annual basis. 
Significant associations $(p<0.05)$ with respect to income were also observed. Respondents with an income less than AED 20,000 were less aware of the seriousness of food wastage $(78.4 \%)$ compared to respondents with an income equivalent to or more than that amount $(>89 \%)$. This was also observed by Limon and Villarino [48]. In this study, respondents belonging to the low-income category $(<20,000$ AED) were significantly less exposed to information about how much food is thrown out $(61.9 \%)$ compared to those with an income equivalent to or greater than AED 20,000 (>70\%). About 14\% and $7 \%$ of the respondents with an income of $>40,000$ AED and $<20,000$ AED, respectively, reported they would never buy an item not on the shopping list despite special offers being present. In comparison, $98.5 \%$ of the respondents with an income between AED 20,000 and AED 40,000 reported they would buy the product with a special offer despite it not being on the list. This is reasonable, since respondents with the lowest income levels $(<20,000$ AED) would try to save as much as possible without budging on offers, while the respondents with the highest incomes $(>40,000 \mathrm{AED})$ can afford to buy products sans offers, and therefore offers probably do not excite them as much. Respondents with an income of AED 20,000-40,000 are thus more likely to take deals. On a similar note, $55.8 \%$ of the respondents with an income of $<20,000$ AED prepared the exact amounts of food needed for consumption, while only $38.3 \%$ of the respondents with an income of $>40,000$ AED did so. These results echo a similar observation to a study conducted previously [49], where it was observed that the economic recession played a major role in hampering food spending behavior. A similar effect was observed during the COVID-19 pandemic, where $85 \%$ of the consumers reported not throwing any food [15]. Moreover, it was noticed that people were concerned about food wastage more so because it was a waste of their money than because of its effect on the environment or the guilt associated with throwing away food [50].

Classifying the associations by gender $(p<0.05)$, about $55.2 \%$ of females reported that they 'often' took measures to reduce food wastage; in comparison $45.8 \%$ of males reported doing so. Previous studies indicated that females were more likely to be concerned about food wastage $[17,20,43]$. The percentage of leftovers was reported to be $2.7 \%$ in females compared to $8.4 \%$ in males. The percentage of females reporting 'feeling uncomfortable' upon discarding food was higher (84.4\%) compared to their male counterparts $(71.1 \%)$.

In one study, participants were shown some form of graphic material related to food waste [51]. The respondents reported feeling disgusted/sorry for their behavior and decided to not throw food, pay attention on their buying behavior, change their shopping habits, and respect the environment. Thus, it is probable that social media users stumble upon such material, and this impacts their attitude towards food wastage. Hence, this variable was also studied. About $66 \%$ of the respondents had heard/seen information concerning food wastage. Around $52 \%, 33.5 \%, 18.9 \%$, and $20.6 \%$ of the respondents in the present study had heard about/seen how much food is thrown out and how to avoid throwing food, regarding food expiry date labels and composting, respectively (Figure 2). In the USA, $42 \%$ of the respondents reported seeing/hearing information pertaining to food waste [42].

In this study, the impact of social media usage on food wastage was somewhat bifurcated. On one hand, using social media was significantly $(p<0.05)$ associated with measuring the exact quantity of ingredients prior to preparation (this would prevent unnecessary excess preparation and thereby reduce food wastage (Table 2)), lower overall family wastage, eating leftovers and composting. 'Rare' users of social media i.e., those who did not check it on a 'daily' or an 'hourly' basis never measured the exact amount of food prior to preparation, while $55.4 \%$ of the 'daily' users recorded doing so. However, the number of hours spent on social media had significant effect $(p<0.05)$ (Table 3$)$, with users who spent less than $2 \mathrm{~h}$ being more likely $(53.0 \%)$ to measure the exact amount required for food preparation compared to users who spent $5 \mathrm{~h}$ or more (37.7\%). Moreover, 'daily' and 'hourly' users' family wastage was lower (31.1 and 34.1\%, respectively) compared to 'rare' users who threw away food half the time. This is probably because $78.8 \%$ and $68.8 \%$ of the 'daily and 'hourly' users ate their leftovers the next day, respectively, while only $50 \%$ of 
the 'rare' users did so. Regarding composting, about $11.3 \%$ of $3-5 \mathrm{~h}$ users performed this activity, while only $6 \%$ of the $<2 \mathrm{~h}$ users did so.

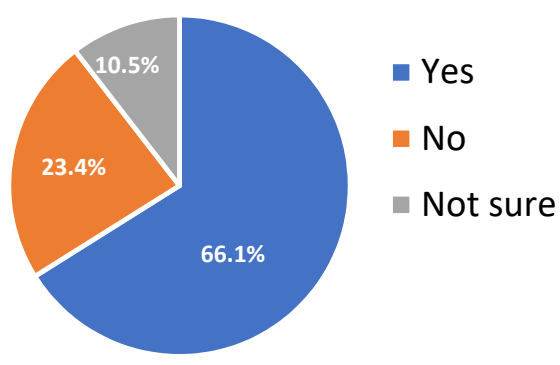

No

Not sure

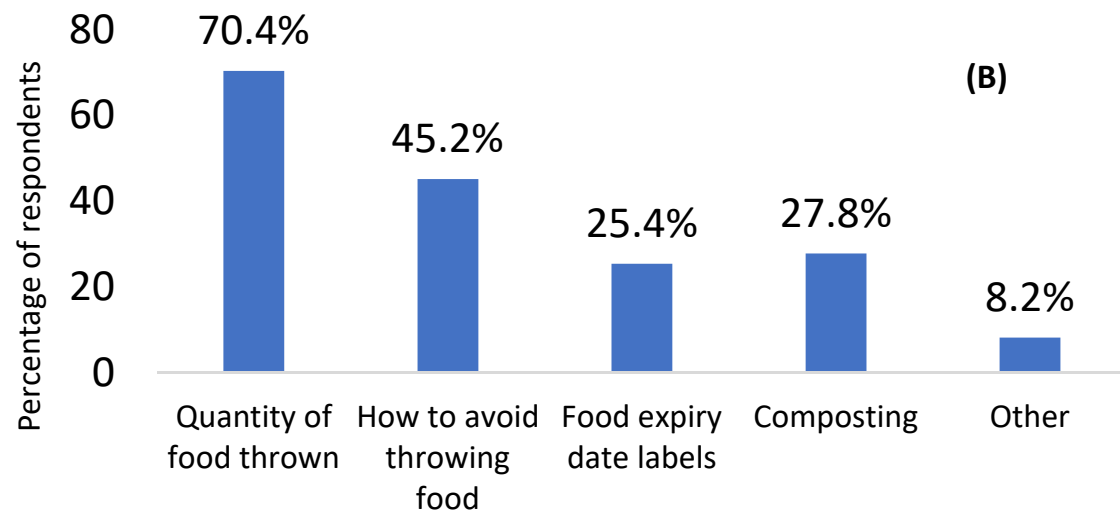

Figure 2. (A) Percentage of respondents who have seen/heard anything about food wastage on social media, (B) type of information respondents saw/heard which pertained to food wastage $(n=525)$.

Table 2. Cross-tabulation of frequency of respondents who check social media and variables pertaining to food wastage $(n=525)$.

\begin{tabular}{|c|c|c|c|c|}
\hline \multirow{2}{*}{$\begin{array}{c}\text { Frequency of } \\
\text { Checking a Social } \\
\text { Media Site }\end{array}$} & \multicolumn{4}{|c|}{ Do You Decide on the Quantity of Food You Will Prepare? } \\
\hline & No, I Don't & $\begin{array}{c}\text { Yes, but I } \\
\text { Overestimate }\end{array}$ & $\begin{array}{c}\text { Yes, but I } \\
\text { Underestimate }\end{array}$ & $\begin{array}{c}\text { Yes, I Measure the } \\
\text { Exact Amount I'll Use }\end{array}$ \\
\hline Hourly & 44 & 116 & 23 & 137 \\
\hline Daily & 18 & 52 & 16 & 107 \\
\hline Rarely & 1 & 2 & 1 & 0 \\
\hline \multicolumn{5}{|c|}{ Do you have leftovers? } \\
\hline & Never & Occasionally & Often & Rarely \\
\hline Hourly & 15 & 125 & 91 & 89 \\
\hline Daily & 2 & 95 & 49 & 47 \\
\hline Rarely & 2 & 1 & 1 & 0 \\
\hline \multicolumn{5}{|c|}{ Do you pay attention to the expiry date? } \\
\hline & No & Not sure & Yes & \\
\hline Hourly & 37 & 25 & 258 & \\
\hline Daily & 10 & 6 & 177 & \\
\hline Rarely & 0 & 0 & 4 & \\
\hline \multicolumn{5}{|c|}{ How much does your family throw away? } \\
\hline & $0 \%$ & $25-50 \%$ & $75-100 \%$ & \\
\hline Hourly & 211 & 103 & 6 & \\
\hline Daily & 133 & 57 & 3 & \\
\hline Rarely & 2 & 1 & 1 & \\
\hline
\end{tabular}


Table 3. Cross tabulation between the time spent on social media sites and variables pertaining to food wastage $(n=525)$.

\begin{tabular}{|c|c|c|c|c|}
\hline \multirow{2}{*}{$\begin{array}{c}\text { Time Spent on Social } \\
\text { Media Sites }\end{array}$} & \multicolumn{4}{|c|}{ Are You Aware of the Seriousness of Food Waste? } \\
\hline & No & Not Sure & Yes & \\
\hline$<2 \mathrm{~h}$ & 10 & 9 & 147 & \\
\hline $3-5 \mathrm{~h}$ & 15 & 12 & 186 & \\
\hline \multirow[t]{2}{*}{$5 \mathrm{~h}+$} & 16 & 20 & 102 & \\
\hline & \multicolumn{4}{|c|}{ Do you think that you use plans to minimize food waste in your daily life? } \\
\hline & No & Not sure & Yes & \\
\hline$<2 \mathrm{~h}$ & 10 & 21 & 135 & \\
\hline $3-5 \mathrm{~h}$ & 25 & 41 & 147 & \\
\hline \multirow[t]{3}{*}{$5 \mathrm{~h}+$} & 27 & 25 & 86 & \\
\hline & \multicolumn{4}{|c|}{ Do you decide on the quantity of food you will prepare? } \\
\hline & No, I don't & Yes, but I overestimate & Yes, but I underestimate & $\begin{array}{l}\text { Yes, I measure the exact } \\
\text { amount I'll use }\end{array}$ \\
\hline$<2 \mathrm{~h}$ & 15 & 47 & 16 & 88 \\
\hline $3-5 \mathrm{~h}$ & 30 & 64 & 16 & 103 \\
\hline $5 \mathrm{~h}+$ & 18 & 59 & 9 & 52 \\
\hline
\end{tabular}

On the other hand, less-frequent social media users significantly $(p<0.05)$ had fewer leftovers, checked expiry dates, were more serious about food wastage, and planned to minimize it. 'Rare', 'daily', and 'hourly' users of social media recorded having leftovers $50 \%, 99 \%$, and $95.3 \%$ of the time. All 'rare' social media users checked the expiry date prior to purchase, while only 80.6 and $91.7 \%$ of the 'hourly' and 'daily' users did so. Those who spent less than $2 \mathrm{~h}$ on social media were more aware of the seriousness of food waste $(88.6 \%)$ compared to those who used it for $5 \mathrm{~h}$ or more $(73.9 \%)$. About $81 \%$ of the participants who used social media for less than $2 \mathrm{~h}$ made plans to minimize food wastage, compared to those $62.3 \%$ with more than $5 \mathrm{~h}$ of social media use. One study reported no significant effect of social media in combating food wastage compared to the control [24]. One reason for the inefficiency of social media in helping reducing food wastage could be due to the very limited number of audiovisual materials dealing with food wastage. An increased number of ads, headlines, etc., dealing with food wastage could make social media a very important tool in combating food waste. Multiple studies reported that if consumers were informed about the effect of food waste on the environment and economy, or even tips and tricks to deal with leftovers, it would encourage them to waste less $[15,18,19,27,28,36,42]$. In addition to this, there are various other factors which impact food wastage, such as peer pressure or family environment [52].

About $70 \%$ of those who agreed that food wastage is a problem (Table 4) and understood its seriousness (Table 5) 'planned' in a way such that food wastage could be minimized $(p<0.05)$. The majority of such people $(52.3 \%)$ bought food as per their needs and ate any leftovers the next day $(74.2 \%)$. About $55 \%$ of such individuals who agreed that food wastage is a problem reported taking measures on an 'often' basis to reduce the amounts they threw away. About $48 \%$ of them measured the exact quantity of food prior to its preparation. About $43.4 \%$ reported having leftovers only on an 'occasional' basis. Consumers who were concerned about food wastage wasted an average of $0.37 \mathrm{~kg}$, while those who were not concerned wasted $0.74 \mathrm{~kg}$ of food [20]. Moreover, the 'concerned' category tended to waste food due to unavoidable reasons, unlike their counterparts.

The results of this study indicate that there is a strong need to educate the public about the seriousness and impact of food waste. This could easily be achieved by targeting social media. Concentrating social media posts on the monetary benefit of not wasting food, rather than cultural or environmental factors, could be of greater benefit [50]. 
Table 4. Cross-tabulation between the agreement that food wastage is a problem and variables pertaining to food wastage $(n=525)$.

\begin{tabular}{|c|c|c|c|c|}
\hline \multirow{2}{*}{$\begin{array}{c}\text { Think Food Waste Is a } \\
\text { Problem }\end{array}$} & \multicolumn{4}{|c|}{ Do You Think That You Use Plans to Minimize Food Waste in Your Daily Life? } \\
\hline & No & Not Sure & Yes & \\
\hline No & 6 & 0 & 7 & \\
\hline Not sure & 2 & 5 & 0 & \\
\hline \multirow[t]{2}{*}{ Yes } & 55 & 84 & 366 & \\
\hline & \multicolumn{4}{|c|}{ How often do you undertake any actions to reduce the amount of food you throw away? } \\
\hline & Never & Occasionally & Often & Rarely \\
\hline No & 2 & 7 & 2 & 2 \\
\hline Not sure & 0 & 2 & 3 & 2 \\
\hline \multirow[t]{3}{*}{ Yes } & 12 & 177 & 277 & 39 \\
\hline & \multicolumn{4}{|c|}{ Do you decide on the quantity of food you will prepare? } \\
\hline & No, I don't & Yes, but I overestimate & Yes, but I underestimate & $\begin{array}{l}\text { Yes, I measure the exact } \\
\text { amount I'll use }\end{array}$ \\
\hline No & 1 & 5 & 4 & 3 \\
\hline Not sure & 1 & 4 & 1 & 1 \\
\hline \multirow[t]{3}{*}{ Yes } & 62 & 162 & 39 & 242 \\
\hline & \multicolumn{4}{|c|}{ Do you have leftovers? } \\
\hline & Never & Occasionally & Often & Rarely \\
\hline No & 4 & 6 & 3 & 0 \\
\hline Not sure & 0 & 1 & 5 & 1 \\
\hline Yes & 15 & 219 & 136 & 135 \\
\hline
\end{tabular}

Table 5. Cross-tabulation between awareness of the seriousness of food wastage and other variables pertaining to it $(n=525)$.

\begin{tabular}{|c|c|c|c|c|}
\hline \multirow{2}{*}{$\begin{array}{l}\text { Awareness about the } \\
\text { Seriousness of Food Waste }\end{array}$} & \multicolumn{4}{|c|}{ Use Plans to Minimize Food Waste in Your Daily Life? } \\
\hline & No & Not Sure & Yes & \\
\hline No & 12 & 7 & 22 & \\
\hline Not sure & 8 & 12 & 22 & \\
\hline \multirow[t]{3}{*}{ Yes } & 43 & 70 & 329 & \\
\hline & \multicolumn{4}{|c|}{ When visiting a shop do you buy food according to a set meal plan? } \\
\hline & No & Not sure & Yes & \\
\hline No & 18 & 9 & 14 & \\
\hline Not sure & 26 & 5 & 11 & \\
\hline \multirow[t]{3}{*}{ Yes } & 152 & 59 & 231 & \\
\hline & \multicolumn{4}{|c|}{ What do you do with the leftovers? } \\
\hline & Discard them & Eat themnext day & Give them away & Freeze them \\
\hline No & 8 & 20 & 18 & 5 \\
\hline Not sure & 8 & 33 & 22 & 10 \\
\hline Yes & 60 & 328 & 186 & 88 \\
\hline
\end{tabular}

In addition to the above-mentioned factors, other variables that have an impact on food wastage include the summer season, yearning to consume fresh food, personal belief systems (a person who experienced a severe foodborne illness is more likely to discard food which does not smell/taste/look good), health/safety protocols/belief systems which prevent sharing food, extravagant cooking behavior, not liking the food, damaged packaging, or even the frequency of situations where preplanned meal cook- 
ing needs to be cancelled (e.g., due to sickness or surprise visitors); all increase food wastage $[15,16,18,25,27,40,42,51,53-55]$. In another study, it was observed that when women were solely responsible for grocery shopping, food wastage was higher [47]. A buffet [56] and table d'hote [57] system were more likely to result in increased wastage.

The magnitude of the problem that food wastage poses was described in detail earlier. The Food and Agriculture Organization (FAO) aims to reduce per capita global food waste by half in the next ten years [58]. Food wastage is an even greater problem for the UAE, because its weather conditions and soil quality are not conducive for agriculture [21]. No evergreen natural rivers/lakes flow through the region. The country is highly dependent on imports. Reducing food wastage would reduce unnecessary import costs and provide budgets for other needs. To achieve this aim, the factors associated with food wastage need to be explored in depth, which this study precisely aims to do.

The majority of the respondents in this study were females. This was probably because females in the UAE (as other Arab countries) are culturally more involved with food preparation and cooking compared to their male counterparts. A more comprehensive study incorporating males is further needed. Moreover, those households which hire housemaids for handling the kitchen may not know of the actual quantities of food being wasted.

\section{Conclusions}

Almost all of the respondents in this study $(96 \%, n=505)$ were aware of the problem that food wastage poses. More than half of the sample took action on a regular basis to reduce it $(53.7 \%, n=282)$, such as (but not limited to) buying food as per their needs $(48.8 \%, n=256)$, eating leftovers $(72.6 \%, n=381)$, and not discarding anything from the last meal $(66.7 \%, n=350)$. Social media played a mixed role in helping to combat food wastage. Increasing the frequency of information related to food waste could make it a major contributing variable. Further studies which use social media as an interventional strategy to prevent food wastage are needed to better understand their association. In this study, a limitation was that a test-retest was not performed. In addition, the probability of a social desirability and recall bias cannot be ruled out.

Author Contributions: Conceptualization, T.M.O., R.S.O.; methodology, R.A. (Russul Alqutub), R.A. (Rawya Akkila), A.H., A.D. and S.D.; writing-original draft preparation, T.M.O., F.H. and M.H.; writing-review and editing, A.A.A.-N., S.T. and L.C.I.; supervision/project administration, T.M.O., R.S.O. All authors have read and agreed to the published version of the manuscript.

Funding: This research received no external funding.

Informed Consent Statement: Written informed consent has been obtained from the participants to publish this paper.

Data Availability Statement: The questionnaire/data presented in this study are available on request from the corresponding author.

Acknowledgments: The authors would like to thank the respondents who participated in the study. The authors also thank University of Sharjah and Jordan University of Science and Technology.

Conflicts of Interest: The authors declare no conflict of interest.

\section{References}

1. GuGustavsson, J.; Cederberg, C.; Sonesson, U.; van Otterdijk, R.; Meybeck, A. Global Food Losses and Food Waste Save; Food Congress: Düsseldorf, Germany, 2011; pp. 1-37.

2. FAO. The Future of Food and Agriculture: Trends and Challenges. Available online: https://books.google.ae/books?id= SRFfDwAAQBAJ (accessed on 14 December 2021).

3. Scialabba, N.; Müller, A.; Schader, C.; Schmidt, U.; Schwegler, P.; Fujiwara, D.; Ghoreishi, Y. Food Wastage Footprint: Full-Cost Accounting (Final Report). Available online: https:/ / www.fao.org/3/i3991e/i3991e.pdf (accessed on 14 December 2021).

4. EAD Waste Management. Available online: https://www.ead.gov.ae/storage/Post/files/0ddcde55f035555af0b341b5084ecbc4.pdf (accessed on 14 December 2021).

5. World Food Program 5 Facts about Food Waste and Hunger / World Food Programme. Available online: https://www.wfp.org/ stories / 5-facts-about-food-waste-and-hunger (accessed on 14 December 2021). 
6. Teigiserova, D.A.; Hamelin, L.; Thomsen, M. Towards transparent valorization of food surplus, waste and loss: Clarifying definitions, food waste hierarchy, and role in the circular economy. Sci. Total Environ. 2020, 706, 136033. [CrossRef]

7. Godfray, H.C.J.G.; Beddington, J.R.; Crute, I.R.; Haddad, L.; Lawrence, D.; Muir, J.F.; Pretty, J.; Robinson, S.; Thomas, S.M.; Toulmin, C. Food security: The challenge of feeding 9 billion people. Science 2010, 327, 812-818. [CrossRef]

8. Timmermans, A.J.M.; Ambuko, J.; Belik, W.; Huang, J. Food Losses and Waste in the Context of Sustainable Food Systems. Available online: https:/ / www.fao.org/3/i3901e/i3901e.pdf (accessed on 14 December 2021).

9. Kumar, K.; Yadav, A.N.; Kumar, V.; Vyas, P.; Dhaliwal, H.S. Food waste: A potential bioresource for extraction of nutraceuticals and bioactive compounds. Bioresour. Bioprocess. 2017, 4, 18. [CrossRef]

10. Al-Domi, H.; Al-Rawajfeh, H.; Aboyousif, F.; Yaghi, S.; Mashal, R.; Fakhoury, J. Determining and addressing food plate waste in a group of students at the University of Jordan. Pak. J. Nutr. 2011, 10, 871-878. [CrossRef]

11. Roodhuyzen, D.M.A.; Luning, P.A.; Fogliano, V.; Steenbekkers, L.P.A. Putting together the puzzle of consumer food waste: Towards an integral perspective. Trends Food Sci. Technol. 2017, 68, 37-50. [CrossRef]

12. Hunger the Environmental Impact of Food Waste. Available online: https://moveforhunger.org/the-environmental-impact-offood-waste (accessed on 14 December 2021).

13. Lins, M.; Zandonadi, R.P.; Strasburg, V.J.; Nakano, E.Y.; Botelho, R.B.A.; Raposo, A.; Ginani, V.C. Eco-Inefficiency Formula: A Method to Verify the Cost of the Economic, Environmental, and Social Impact of Waste in Food Services. Foods 2021, $10,1369$. [CrossRef]

14. Lins, M.; Puppin Zandonadi, R.; Raposo, A.; Ginani, V.C. Food Waste on Foodservice: An Overview through the Perspective of Sustainable Dimensions. Foods 2021, 10, 1175. [CrossRef]

15. Jribi, S.; Ben Ismail, H.; Doggui, D.; Debbabi, H. COVID-19 virus outbreak lockdown: What impacts on household food wastage? Environ. Dev. Sustain. 2020, 22, 3939-3955. [CrossRef]

16. Macková, M.; Hazuchová, N.; Stávková, J. Czech consumers' attitudes to food waste. Agric. Econ. 2019, 65, 314-321. [CrossRef]

17. Marangon, F.; Tempesta, T.; Troiano, S.; Vecchiato, D. Food waste, consumer attitudes and behaviour. A study in the North-Eastern part of Italy. Ital. Rev. Agric. Econ. 2014, 69, 201-209.

18. Berjan, S.; Mrdalj, V.; El Bilali, H.; Velimirovic, A.; Blagojevic, Z.; Bottalico, F.; Debs, P.; Capone, R. Household food waste in Montenegro. Ital. J. Food Sci. 2019, 31, 274-287.

19. Preka, R.; Berjan, S.; Capone, R.; El Bilali, H.; Allahyari, M.S.; Debs, P.; Bottalico, F.; Mrdalj, V. Household food wastage in Albania: Causes, extent and implications. Future Food J. Food Agric. Soc. 2020, 8, 1-20.

20. Flanagan, A.; Priyadarshini, A. A study of consumer behaviour towards food-waste in Ireland: Attitudes, quantities and global warming potentials. J. Environ. Manag. 2021, 284, 112046. [CrossRef]

21. CIA. The World Factbook. Available online: https://www.cia.gov/the-world-factbook/countries/united-arab-emirates (accessed on 14 December 2021).

22. Winnow Ways to Manage Large Scale Food Waste. Available online: https: / info.winnowsolutions.com/food-waste-management (accessed on 3 January 2022).

23. Food Bank, U. The UAE Food Bank Initiative. Available online: https:/ / www.dm.gov.ae/foodbank/ (accessed on 3 January 2022).

24. Young, W.; Russell, S.V.; Robinson, C.A.; Barkemeyer, R. Can social media be a tool for reducing consumers' food waste? A behaviour change experiment by a UK retailer. Resour. Conserv. Recycl. 2017, 117, 195-203. [CrossRef]

25. Farr-Wharton, G.; Foth, M.; Choi, J.H. Identifying factors that promote consumer behaviours causing expired domestic food waste. J. Consum. Behav. 2014, 13, 393-402. [CrossRef]

26. Bank, W. Literacy Rate-Adult Total-United Arab Emirates. Available online: https://data.worldbank.org/indicator/SE.ADT. LITR.ZS?locations=AE (accessed on 3 January 2022).

27. Bogevska, Z.; Berjan, S.; Capone, R.; Debs, P.; El Bilali, H.; Bottalico, F.; Davitkovska, M. Household food wastage in North Macedonia. Agric. For. Poljopr. I Sumar. 2020, 66, 125-135. [CrossRef]

28. Yildirim, H.; Capone, R.; Karanlik, A.; Bottalico, F.; Debs, P.; El Bilali, H. Food wastage in Turkey: An exploratory survey on household food waste. J. Food Nutr. Res. 2016, 4, 483-489.

29. Cooper, D.R.; Schindler, P.S.; Sun, J. Business Research Methods; Mcgraw-hill New York: New York, NY, USA, 2006 ; Volume 9.

30. Nunnally, J.C. Psychometric theory-25 years ago and now. Educ. Res. 1975, 4, 7-21.

31. Kadam, P.; Bhalerao, S. Sample size calculation. Int. J. Ayurveda Res. 2010, 1, 55-57.

32. Grandhi, B.; Appaiah Singh, J. What a waste! A study of food wastage behavior in Singapore. J. Food Prod. Mark. 2016, 22, 471-485. [CrossRef]

33. Hanssen, O.J.; Møller, H. Food wastage in Norway 2013. Status Trends 2009, 13, 1-41.

34. Schanes, K.; Dobernig, K.; Gözet, B. Food waste matters-A systematic review of household food waste practices and their policy implications. J. Clean. Prod. 2018, 182, 978-991. [CrossRef]

35. Porpino, G.; Parente, J.; Wansink, B. Food waste paradox: Antecedents of food disposal in low income households. Int. J. Consum. Stud. 2015, 39, 619-629. [CrossRef]

36. Charbel, L.; Capone, R.; Grizi, L.; Debs, P.; Khalife, D.; El Bilali, H.; Bottalico, F. Preliminary insights on household food wastage in Lebanon. J. Food Secur. 2016, 4, 131-137.

37. Lorenz, B.A.-S.; Hartmann, M.; Langen, N. What makes people leave their food? The interaction of personal and situational factors leading to plate leftovers in canteens. Appetite 2017, 116, 45-56. [CrossRef] 
38. Andrews, L.; Kerr, G.; Pearson, D.; Mirosa, M. The attributes of leftovers and higher-order personal values. Br. Food J. 2018, 120, 1965-1979. [CrossRef]

39. Krishna, A.; Hagen, L. Out of proportion? The role of leftovers in eating-related affect and behavior. J. Exp. Soc. Psychol. 2019, 81, 15-26. [CrossRef]

40. Parizeau, K.; von Massow, M.; Martin, R. Household-level dynamics of food waste production and related beliefs, attitudes, and behaviours in Guelph, Ontario. Waste Manag. 2015, 35, 207-217. [CrossRef]

41. Djekic, I.; Miloradovic, Z.; Djekic, S.; Tomasevic, I. Household food waste in Serbia-Attitudes, quantities and global warming potential. J. Clean. Prod. 2019, 229, 44-52. [CrossRef]

42. Neff, R.A.; Spiker, M.L.; Truant, P.L. Wasted food: US consumers' reported awareness, attitudes, and behaviors. PLoS ONE 2015, 10, e0127881. [CrossRef]

43. Marais, M.L.; Smit, Y.; Koen, N.; Lötze, E. Are the attitudes and practices of foodservice managers, catering personnel and students contributing to excessive food wastage at Stellenbosch University? S. Afr. J. Clin. Nutr. 2017, 30, 15-22. [CrossRef]

44. Williams, H.; Wikström, F.; Otterbring, T.; Löfgren, M.; Gustafsson, A. Reasons for household food waste with special attention to packaging. J. Clean. Prod. 2012, 24, 141-148. [CrossRef]

45. Stefan, V.; van Herpen, E.; Tudoran, A.A.; Lähteenmäki, L. Avoiding food waste by Romanian consumers: The importance of planning and shopping routines. Food Qual. Prefer. 2013, 28, 375-381. [CrossRef]

46. Goh, E.; Jie, F. To waste or not to waste: Exploring motivational factors of Generation Z hospitality employees towards food wastage in the hospitality industry. Int. J. Hosp. Manag. 2019, 80, 126-135. [CrossRef]

47. Koivupuro, H.; Hartikainen, H.; Silvennoinen, K.; Katajajuuri, J.; Heikintalo, N.; Reinikainen, A.; Jalkanen, L. Influence of socio-demographical, behavioural and attitudinal factors on the amount of avoidable food waste generated in Finnish households. Int. J. Consum. Stud. 2012, 36, 183-191. [CrossRef]

48. Limon, M.R.; Villarino, C.B.J. Knowledge, attitudes and practices on household food waste: Bases for formulation of a recycling system. Glob. J. Environ. Sci. Manag. 2020, 6, 323-340.

49. Abeliotis, K.; Lasaridi, K.; Chroni, C. Attitudes and behaviour of Greek households regarding food waste prevention. Waste Manag. Res. 2014, 32, 237-240. [CrossRef]

50. Quested, T.E.; Marsh, E.; Stunell, D.; Parry, A.D. Spaghetti soup: The complex world of food waste behaviours. Resour. Conserv. Recycl. 2013, 79, 43-51. [CrossRef]

51. Radzymińska, M.; Jakubowska, D.; Staniewska, K. Consumer attitude and behaviour towards food waste. J. Agribus. Rural Dev. 2016, 39, 175-181. [CrossRef]

52. Mganga, P.; Syafrudin, S.; Amirudin, A. A Survey of Students' Awareness on Food Waste Problems and Their Behaviour towards Food Wastage: A Case Study of Diponegoro University (UNDIP), Indonesia; EDP Sciences: Les Ulis, France, 2021; Volume 317, pp. 1-9.

53. Srivastava, M.; Srivastava, S.K. Examining the relevance of emotions for regulation of food wastage behaviour: A research agenda. Soc. Bus. 2020, 10, 151-171. [CrossRef]

54. Lazell, J. Identifying the Barriers and Opportunities for Food Waste Prevention in Universities: Using Social Media as a Tool for Behaviour Change; Coventry University: West Midlands, UK, 2014.

55. Melbye, E.L.; Onozaka, Y.; Hansen, H. Throwing it all away: Exploring affluent consumers' attitudes toward wasting edible food J. Food Prod. Mark. 2017, 23, 416-429. [CrossRef]

56. Tekin, Ö.A.; İLyasov, A. The Food Waste in Five-Star Hotels: A Study on Turkish Guests' Attitudes. J. Tour. Gastron. Stud. 2017, 13, 13-31. [CrossRef]

57. Sandaruwani, J.A.R.C.; Gnanapala, W.K.A.C. Food wastage and its impacts on sustainable business operations: A study on Sri Lankan tourist hotels. Procedia Food Sci. 2016, 6, 133-135. [CrossRef]

58. FAO Food Loss and Food Waste. Available online: http://www.fao.org/food-loss-and-food-waste/flw-data)\#: \{\}:text=In (accessed on 14 December 2021). 